\title{
A Revision of the Oriental and Australasian Medetera (Diptera: Dolichopodidae)
}

\author{
DANIEL J. BICKEL \\ Australian Museum, \\ P.O. Box A285, Sydney South, NSW 2000, Australia
}

\begin{abstract}
The Oriental and Australasian Medetera (Diptera: Dolichopodidae) are revised and 61 species are recognized, 43 of them new, with 27 Oriental, 29 Australasian, and 5 species occurring in both zoogeographical regions. All species are described and figured except $M$. adsumpta Becker, $M$. nudicoxa Becker and $M$. longa Becker, which were not seen. A key is provided for the separation of males.

The following species are newly placed in synonomy: $M$. atrata Van Duzee, $M$. cilifemorata Van Duzee, $M$. hawaiiensis Van Duzee and M. palmae Hardy ( $=M$. grisescens de Meijere); and Elongomedetera thoracica Hollis $(=M$. gracilis Parent). Lectotypes are designated for $M$. apicipes de Meijere, $M$. grisescens de Meijere, $M$. longitarsis de Meijere, $M$. minima de Meijere, M. olivacea de Meijere, M. opaca de Meijere, M. platychira de Meijere, M. pumila de Meijere and M. vivida Becker. A neotype is designated for M. femoralis Becker. Medetera comes Hardy and M. extranea Becker are regarded as nomina dubia. Micromorphus vegandris (Frey) is a new combination for Medetera vegandris Frey.

Of particular interest is the secondary segmentation and articulation of the male cercus in the salomonis group, unique among Brachycera. Here the cercus has been divided into discrete basal and distal sections, with the distal section freely articulated on basal section.

Three high altitude species from Nepal have relatively long and broad wings. Several species have orientated silvery pruinosity.

A phylogenetic analysis of the major Medetera species groups is presented.

The Australasian Medetera fauna, although with distinctive elements, is derived from the Oriental fauna. The Pacific Ocean has progressively fewer species moving eastwards from the Oriental-Australasian source area. Medetera grisescens is a widespread tramp species, from the western Indian Ocean to Hawaii, while the Australasian M. salomonis ranges from French Polynesia to the Philippines. Elements from the predominantly holarctic apicalis and diademaveles groups are present in the Orient and Australasia. Medetera kinabaluensis, from high elevation in Sabah, belongs to the circumboreal, primarily conifer-associated scolytid predator signaticornis-pinicola group. The disjunct distribution of the aberrans group in the Orient and the New World is regarded as a vicariant distribution resulting from progressive cooling and southward retreat of early Tertiary circumboreal warm mesophytic forests.
\end{abstract}

BICKEL, DANIEL J., 1987. A revision of the Oriental and Australasian Medetera (Diptera: Dolichopodidae). Records of the Australian Museum 39(4): 195-259.

\section{Contents}

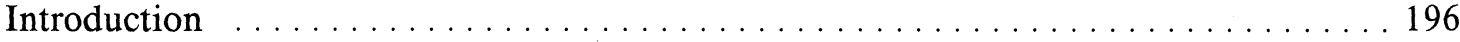

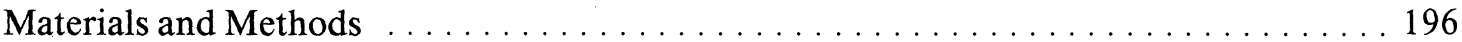

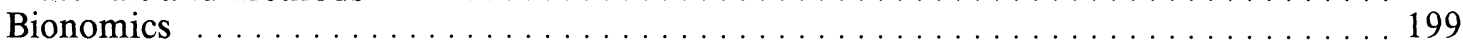

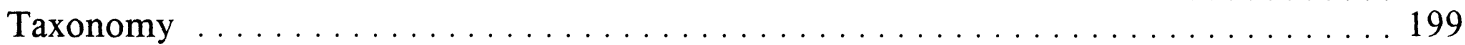

Morphological Notes . . . . . . . . . . . . . . . . . . . . . . . . . . . . . . . 200 